Authors' post-print (i.e., final draft post refereeing)

published as:

Van Steenwinkel, I., Dierckx de Casterlé, B., \& Heylighen, A. (2017). How architectural design affords experiences of freedom in residential care for older people. Journal of Aging Studies. 


\title{
How architectural design affords experiences of freedom in residential care for older people
}

Iris Van Steenwinkel, Bernadette Dierckx de Casterlé, and Ann Heylighen KU Leuven, Belgium

\begin{abstract}
Human values and social issues shape visions on dwelling and care for older people, a growing number of whom live in residential care facilities. These facilities' architectural design is considered to play an important role in realizing care visions. This role, however, has received little attention in research.
\end{abstract}

This article presents a case study of a residential care facility for which the architects made considerable effort to match the design with the care vision. The study offers insights into residents' and caregivers' experiences of, respectively, living and working in this facility, and the role of architectural features therein.

A single qualitative case study design was used to provide in-depth, contextual insights. The methods include semi-structured interviews with residents and caregivers, and participant observation. Data concerning design intentions, assumptions and strategies were obtained from design documents, through a semi-structured interview with the architects, and observations on site.

Our analysis underlines the importance of freedom (and especially freedom of movement), and the balance between experiencing freedom and being bound to a social and physical framework. It shows the architecture features that can have a role therein: small-scaleness in terms of number of residents per dwelling unit, size and compactness; spatial generosity in terms of surface area, room to maneuver and variety of places; and physical accessibility. Our study challenges the idea of familylike group living. Since we found limited sense of group belonging amongst residents, our findings suggest to rethink residential care facilities in terms of private or collective living in order to address residents' social freedom of movement. Caregivers associated 'hominess' with freedom of movement, action and choice, with favorable social dynamics and with the building's residential character. Being perceived as homey, the facility's architectural design matches caregivers' care vision and, thus, helped them realizing this vision.

\section{Keywords}

architectural design; residential care facility; older people; experience; freedom; care visions 


\section{Introduction}

Worldwide, the number of older people is rising (United Nations, Department of Economic and Social Affairs, 2015). Because health status typically declines with advancing age, the need grows for long-term care, like provided in residential care facilities (United Nations, Department of Economic and Social Affairs, 2015; Van den Bosch et al., 2011). Ideally, these facilities meet contemporary care visions.

Societal discourses on dwelling and care for older people reflect an evolution from a medical to a social model (Declercq, 2000; Elf et al., 2015; Mens \& Wagenaar, 2009; van der Kooij, 1987).

Originating in early $20^{\text {th }}$ century modernism, the former takes a rational, objective, functional and pathological approach to care. Older people are categorized based on medical parameters or care needs. This model is associated with patronizing, stigmatization, institutionalization, exclusion and lack of recognition of personal characteristics, values and perspectives. The corresponding architecture lacks places relating to residents" daily life: "in a classical nursing home, people do not dwell" (Mens \& Wagenaar, 2009, p. 79, authors' translation). By contrast, the social model emphasizes people's autonomy, individuality, community integration and participation, normalization, and home (versus institution) (Declercq, 2000; Mens \& Wagenaar, 2009). Increasing attention goes to older people's experiences. The ongoing refutation of a purely medical model evidences an emancipation process of older people who want to avoid institutionalization (i.e., avoid subjection to institutional rules and routines, and to restrictions of activities, mobility and social contacts), and instead want their voice to be heard, continue their own daily lives, and stay involved in society as much as possible (Mens \& Wagenaar, 2009). The physical environment plays an important role in realizing care visions (Elf, Fröst, Lindahl, \& Wijk, 2015; Kearns, 2007; Martin, Nettleton, Buse, Prior, \& Twigg, 2015; Mens \& Wagenaar, 2009; Van Steenwinkel, Verstraeten, \& Heylighen, 2016).

Theoretically, environmental gerontology puts forward several models to develop understandings of relations between people and their physical environment. The competence-press model (Lawton \& Nahemow, 1973), for example, plots the press exerted by the environment (broadly defined) that older people can manage in relation to their competence level. Another model by Parmelee and Lawton (1990) suggests that at the heart of person-environment relations in late life lies the dialectic of autonomy and security (following citations, see Parmelee \& Lawton, 1990, p. 465-466). They define autonomy as "a state in which the person is, or feels, capable of pursuing life goals by the use of his or her own resources", and which implies "freedom of choice, action, and self-regulation of one's life space - in other words, the perception of and capacity for effective independent action". Security is "a state in which pursuit of life goals is linked to, limited by, and aided by dependable physical, social, and interpersonal resources." Security includes physical safety, social support, and peace of mind, for example, being free "from risk, danger, concern, or doubt."

Besides a focus on processes (like environmental stress, and competence), increasing attention goes to 'place' as a "key integrative construct in conceptualizing both the environments occupied by older persons and older person's interaction with these environments" (Wahl \& Weisman, 2003, p. 625). A well-known model of place by Weisman et al. (Weisman, 1997; Weisman, Calkins, \& Sloane, 1994; Weisman, Chaudhury, \& Diaz Moore, 2000) considers the people studied in their physical, social, and care organizational context. Diaz Moore (2004, p. 298), following Gubrium (1978), defines place as "a milieu comprising a physical setting within which activities occur - which can be thought to be carried out by people of various social groups - and having inherent yet largely implicit socially shared understandings that enable effective coaction". In connection with the meaning of places in late life, the concepts home, identity, and privacy are well-researched (e.g., Rowles \& Chaudhury, 2005). 
However, theories within environmental gerontology have been criticized for being not very productive (Wahl \& Weisman, 2003, p. 626). The worldviews underlying these theories may hamper research innovation and compatibility of knowledge with design practice (Diaz Moore \& Geboy, 2010; Schwarz, 2012; Wahl \& Weisman, 2003). Indeed, Schwarz (2012, p. 6) notes, by emphasizing a positivistic approach, environmental gerontology focused on predictive, context-independent theories that fail to offer insight into the role of the physical environment as a contextual element in the aging process and in older people's experiences.

In line with Schwarz (2012) we recognize the potential of studying cases that are connected with their context, to develop in-depth understandings of how and why older people experience and negotiate their physical environment the way they do. Such understandings should not aim to be predictive, since people have certain degrees of freedom in making sense of and negotiating their environment. The environment thus has no deterministic force. The understandings developed can help to gain insight into and anticipate similar situations and envision alternative futures (Flyvbjerg, 2011, p. 312; Geertz, 1993, p. 26), and can in this way be relevant to architectural design research and practice.

This article presents a case study of a newly-built residential care facility for older people - referred to as Heather House (pseudonym) - for which the architects made considerable effort to match the design with the care vision. We aimed to gain insight into residents' and caregivers' experiences of, respectively, living and working in Heather House, and the role of architectural features in these experiences.

\section{Methods}

The first author collected data and analyzed them in collaboration with the second and third author, and is henceforth referred to as "the researcher."

Because we aim to articulate an in-depth understanding of architecture's role in people's experiences, the research consists of a case narrative with a critical realist and constructionist (Crotty, 1998) approach. Two data gathering techniques were used: participant observation and indepth, semi-structured interviews with residents and caregivers. For interview preparation and for contextual information, data concerning design intentions, assumptions and strategies were obtained from the design brief, and architects' design contest submission, and through a semistructured interview with them, and observations on site.

\section{Setting}

Heather House is a residential care facility for people with physical impairments, psychosocial problems, dementia, and psychiatric problems due to old age, in use since May 2014. It is located in a multicultural garden suburb, and includes four dwelling units for eight residents each. During one week, four nursing assistants individually manage one dwelling unit. Per four dwelling units there are five nurses, one occupational therapist, and four cleaners. Additionally, help is offered by interns (about five per year), and family members. Residents can use a paid service from a non-profit organization, e.g., to assist in activities or transportation.

Heather House was selected for its contemporary care vision and its innovative architectural design. Its care vision aligns with 'small-scale, normalized living', a well-known concept in Flanders, Belgium, denoting a housing and care type where six to 16 people, with professional guidance, form a household in a for them familiar and homey environment, which is architecturally and/or socially integrated in the neighborhood (Van Audenhove et al., 2003). In their care vision, directors of Heather House emphasize normalization, integration, participation, and family-like group living 
within a household. They aim to house eight people per dwelling unit in a familiar, homey environment that offers common places and ample privacy. They aim to offer an environment that compensates for residents' impairments, supports them in conducting homey activities and moving independently and safely, affords social freedom of movement, and integrates residents in the neighborhood. According to the care vision, residents' daily life is not bound by fixed care tasks, rather, much can be chosen and decided by themselves.

The architects took as the starting point for their design dwelling (rather than care logistics). Each dwelling unit consists of well-lit dwelling places compactly clustered around a patio in an open plan (i.e., a continuous space without doors) (Figure 1, b, c). Two adjoining private rooms - designed to be little houses in themselves, with an entrance, sitting corner, bedroom and bathroom (Figure 1, d) - give way to an entrance, living room, hobby room, or kitchen-dining area. These common rooms are scaled to accommodate eight residents, each with a stroller and wheelchair. Four of these dwelling units are grouped in two building blocks of two floors high, connected with a bridge on the first floor. Their front doors face each other. The basement contains a bathroom for residents, and staff's utility and storage rooms. A garden path connects the garden gates, (front) doors and terraces (Figure 1, e). To integrate Heather House in the residential area, the building stands along the street (rather than drawing back from it), and its façade is articulated into smaller parts with pitched roofs, and varying windows (Figure 1, a), like the neighboring houses. Additionally, the site and building include residential elements like an hedge, garden path, garden gate, and front door with a lamp. 


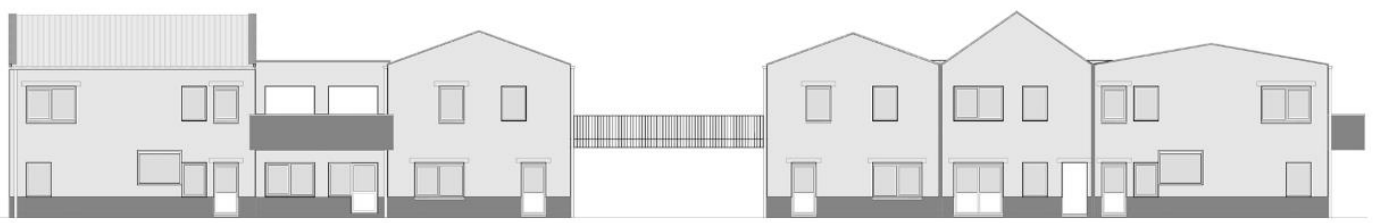

b
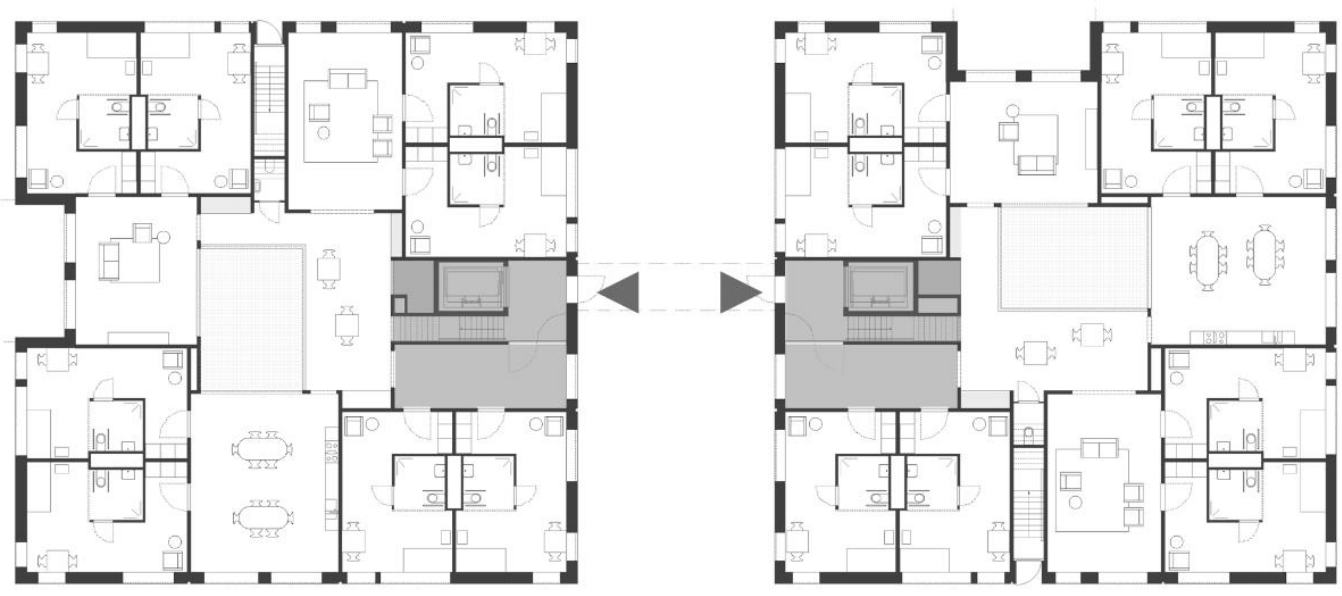

C

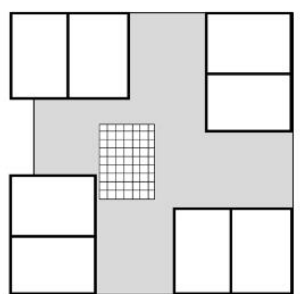

d

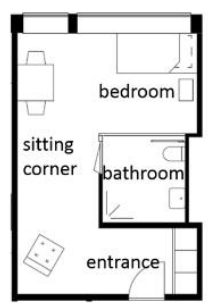

e

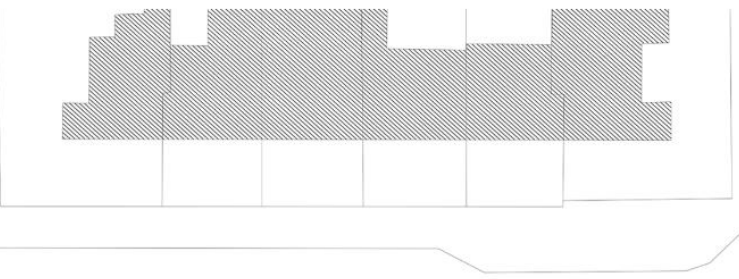

$$
\text { e }
$$

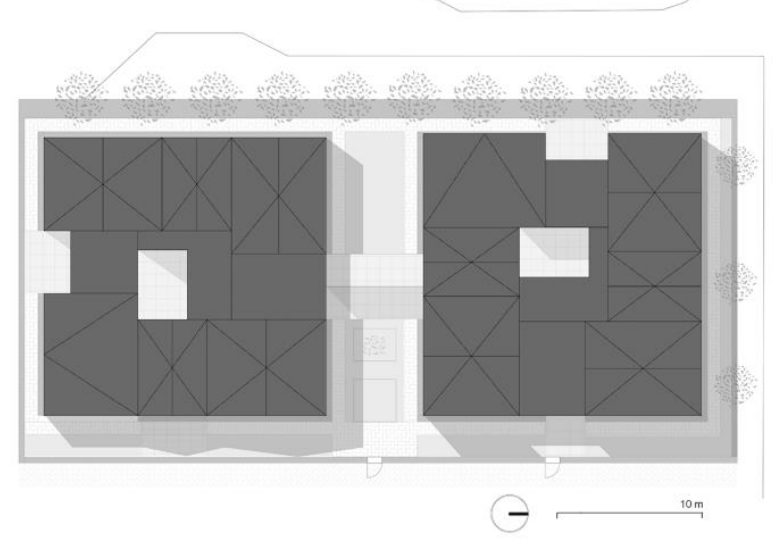

Figure 1: a) The east façade is articulated into smaller parts, with pitched roofs, and varying windows; b) The ground floor includes two similar dwelling units. They are differently orientated so that their entrances (marked in grey and with arrows) face each other; c) Basic spatial organizational principle of one dwelling unit: private rooms clustered around a patio create space for multiple common rooms arranged in an open plan; d) A private room with an entrance, sitting corner, bedroom and bathroom; e) The site plan shows outdoor places, garden paths, the street and neighboring houses. 


\section{Sample}

Convenience sampling was used. Residents living in the two dwelling units where participant observation took place, and nursing assistants of all four dwelling units were included. Residents cognitively unable to participate in interviews, or not speaking Dutch were excluded. Residents were chosen based on the researcher's informal contacts with them during participant observation, and in consultation with caregivers. Table 1 andTable 2 respectively show the diversity in interviewed residents' and caregivers' characteristics.

Seven residents and seven caregivers were interviewed. The number of participants was decided during the study, based on the richness of the interviews. In combination with participant observation, the interviews offered sufficient material to explore the role of architectural features in residents' and caregivers' experiences.

Table 1

residents' characteristics

\begin{tabular}{ll}
\hline Sex & 3 women, 4 men \\
Age & $63-84$ \\
Origin & 6 from the region where Heather House is located, 1 from \\
& a city about $90 \mathrm{~km}$ away \\
Education level & $4:$ elementary school (until age 14); 2 : secondary school; \\
& 1: higher education \\
Previous stay in another care facility & $6:$ yes; 1 no \\
Stay in Heather House & 6 since Heather House's opening or a little later $(+/-1,5$ \\
& year); 1 since 11 months \\
\hline
\end{tabular}

Table 2

caregivers' characteristics

\begin{tabular}{ll}
\hline Sex & 6 women, 2 men \\
Age & $25-55$ \\
work experience as work assistant & $2-37$ years \\
work experience in Heather House & 6 weeks $-1,5$ year \\
\hline
\end{tabular}

\section{Data collection}

Data collected include notes, pictures, audio recordings and verbatim transcriptions.

Participant observation focused on how daily activities of residents and caregivers took place within the physical setting of Heather House. The researchers' participation included, e.g., talking to residents and caregivers, joining residents having lunch, playing a round game, or going out for a walk. She took notes on a laptop at the table in the hobby room or in an armchair, similar to how caregivers do their administrative tasks. The observations allowed to become acquainted with residents and caregivers, with the architecture and care organization, and with concrete dwelling and care related activities. In that way, the observations helped to better understand and interpret interview data within their context.

In the interviews, residents were first asked to recount their knowledge and expectations of Heather House before moving in, and their reasons for moving. They were also asked to describe the building (their first and later impressions), and experienced similarities or differences with other buildings; 
how it was for them to live in Heather House; the things they did or would have liked to do. Caregivers were also first asked to describe the building (their first and later impressions); whether and how their daily work matched their image of Heather House; how it was for them to work there; their role in the dwelling unit, whether they fully succeeded in fulfilling it; and what they find important in their job. For each of these questions, additional questions were asked to probe into relations with the potentials and limitations afforded by the building's architecture.

Second, residents and caregivers were explicitly asked about their experiences with architectural features of the building, e.g., the scale, open plan, number of floors, and the caregivers' desk being integrated within one of the common rooms.

\section{Data analysis}

The analysis mainly focused on interviews with residents and caregivers, complemented by observation notes, and was conducted according to QUAGOL, a guide for qualitative data analysis (Dierckx de Casterlé, Gastmans, Bryon, \& Denier, 2012). QUAGOL covers two parts: (1) coding process preparation, by taking a narrative approach and identifying and reflecting on themes; (2) the actual coding process consists of an interplay between description, analysis, interpretation and developing concepts (Dierckx de Casterlé et al., 2012, p. 369). First, printed transcripts were read, text chunks were highlighted and annotated. Then narrative reports, preliminary conceptual schemes, and code lists were made. Second, qualitative data analysis software NVivo11 (QSR International, 2015) was used to take a systematic approach to identifying empirical support. The software facilitated searching through and organizing data, as well as retrieving data labeled with particular codes. After having been tested against the empirical support, preliminary conceptual schemes were adjusted and further developed, and, finally, described.

Different strategies were used to enhance the findings' trustworthiness. Bracketing was used to counter bias. Methods and data were triangulated by combining participant observation and interviews, and by including both residents' and caregivers' perspectives. The analysis was conducted in consultation and through discussion with the second and third author, who also read transcripts and made narrative reports, and through peer debriefing with academic and professional experts in architecture, care for older people, and organizational studies. Such multidisciplinary teamwork contributes to a deeper and more nuanced understanding of the data (Dierckx de Casterlé et al., 2012, p. 370).

\section{Ethical issues}

This study was approved by the Social and Societal Ethics Committee of the University of Leuven, Belgium. Residents, caregivers, facility directors, and architects were informed about the study orally and in written form, with the opportunity of asking questions.

The researcher was not affiliated with Heather House. Through her doctoral study, she had gained experience in conducting participant observation in a residential care facility and interviewing frail and older people. The interviews with residents were adjusted to each resident's capacities in terms of timing and length, content and wording of questions. Residents were free to participate in the interview alone, or to choose a confidante to join. This could be a family member, friend or professional caregiver who could help with verbal communication, offer emotional support, or suggest to pause or end the interview when noticing any discomfort in the interviewee. All interviewed residents said to feel comfortable in doing the interview alone and gave informed consent. 
In this manuscript, details that might allow identification of participants by externals have been omitted. A pseudonym is used to refer to the residential care facility. However, since graphics are indispensable when analyzing architecture, people familiar with the facility may recognize it.

\section{Findings}

First, we describe residents' and caregivers' experiences, and next, the role of architectural features therein.

\section{Experiences of residents and caregivers}

In both residents' and caregivers' appreciations of Heather House, freedom and social aspects of living together stood out. They considered it important that residents and caregivers maintain certain degrees of freedom in their daily life and work, and that favorable social dynamics exist among them.

Despite variations between residents in the degree of freedom experienced, they felt more free in Heather House than in other facilities they knew. Also, they experienced more favorable social dynamics, although we found amongst residents a limited sense of group belonging. Caregivers' accounts indicate a relation between freedom and favorable social dynamics. They strongly appreciate the facility's hominess, which they associated either with these two, or with the facility's residential character. This hominess helped them realizing their vision on dwelling and care.

\section{Freedom}

Possibilities afforded by the physical environment and/or the care (organizational) context, as recounted in the interviews with residents and caregivers, were subsumed under the theme of freedom. We distinguished three aspects of freedom in the interviews: having the possibility and being allowed to (1) move, (2) act (i.e., perform or join activities of daily life), and (3) choose freely; respectively referred to as freedom of movement, activity and choice. These aspects can be considered intertwined as in, e.g., moving wherever you want for a chosen activity or for meeting particular people.

In interviews with residents, freedom, and especially freedom of movement, was the theme that stood out most. Multiple times, explicitly and spontaneously, they mentioned that in other residential care facilities they had felt less free than in Heather House. Therefore, their experienced freedom in Heather House could be considered as a regained freedom, which can explain why this theme was so outspoken.

For caregivers, freedom is also a very important, if not the most important reason for the positive tenor in their accounts.

Freedom of movement. For both residents and caregivers, residents' freedom of movement concerned the interior of each dwelling unit, i.e., the ease of access to different rooms, and of maneuvering within each room, e.g., around the dining table, or in a resident's private bathroom. For example, one caregiver told:

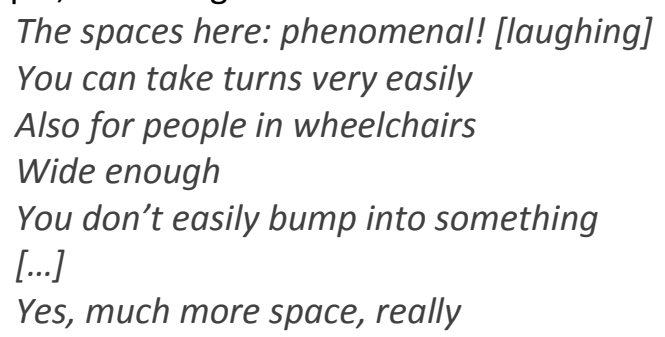

But most important was the possibility for residents to go outdoors independently and whenever they wanted. 


\section{[In the former facility] I couldn't go outside \\ [I could] only walk through that long corridor \\ And when they asked me to move to this place \\ I said: "yes, but I want a room downstairs \\ Not upstairs anymore" \\ yes, because the elevator was always broken \\ And then they said: "yes, you can have a room downstairs" \\ I said: "than we can go tomorrow!" [laughing]}

By extension, freedom of movement concerns on-site relation with and ease of access to the neighborhood. This also concerned visitors, who were welcome anytime, and could take their family member or acquaintance out. The researcher's observations confirmed residents' freedom of movement, e.g.: after lunch, some residents took seats along the patio, another lied down on the sofa in the living room, and others retreated in their room; two befriended residents went for a stroll outside several times a day; one man daily visited his brother who lived in an adjacent dwelling unit; yet another went for a walk in the neighborhood.

Despite overall positive appreciations in residents, the degree of freedom experienced varied between them. In part, this variation may be related to residents' personal characteristics, i.e., their physical capacities (e.g., mobility, sight) and cognitive capacities (e.g., for remembering the code to open the garden gate), their life history and personality. For example, one resident had lived within a convent's boundaries for most of her life and said that for this reason, she did not feel the urge to leave Heather House either. Another resident did miss the ease of access to the neighborhood, and had arguments with caregivers when they had locked doors for safety reasons. He referred to his life in the country side, where he went in and out whenever he pleased, and contrasted his lifestyle with people who had lived in an apartment and stayed more time indoors.

Freedom of activity and choice. Overall, residents seemed to consider freedom of activity and choice very important. This often concerned the flexibility in the regular day schedule, i.e., when to get out of and into bed, and when to eat. In that sense, they appreciated an increased freedom of action and choice compared to other facilities. For three residents, maintaining or regaining freedom also concerned their freedom of choosing a facility. For example, one of them underlined his free citizenship in relation to his choice for one facility or another:

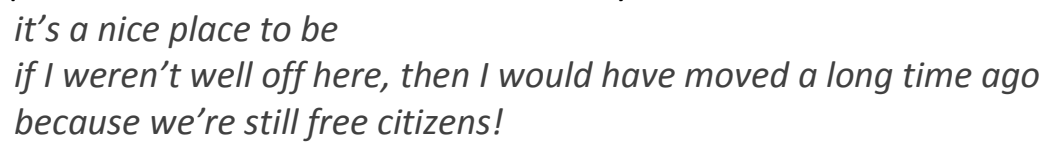

Residents expressed very different experiences concerning their freedom in performing or joining activities of daily life, and choosing freely. This variation may partly relate to their personal relation with caregivers and to finding a balance between freedom and the need for caregivers' support and guidance. Three residents expressed their appreciation of being free and independent, yet finding (social) support when needed. For example:

They [= caregivers] leave you free

And if something is wrong with you

You can share it

Than you can be on friendly terms

Some residents, as observed, were more stimulated by caregivers to join activities. One resident expressed her discontent about being pushed by caregivers to perform household activities:

Yes, like [name of a caregiver] just said:

"here is a dust cloth" [with more recalcitrance in her voice]

"put your hand gloves on"

"wipe your bed" 
Normally the nursing assistants should do that!

Residents' experiences may also vary because of differences in physical and cognitive capacities, and/or because of personal relations among them. For example, one partially sighted resident abided by his incapability of reading the newspaper, watching television and leaving the facility independently. Another found too little activity due to, and amongst his physically and cognitively frail co-residents. Because of a fight with one co-resident, he quitted some household activities that he used to do. Yet another resident - despite differences in capacities with her co-residents experienced having plenty of things to do: setting and clearing the table, eating, emptying the dishwasher, getting the mail, watching television, taking a nap, having coffee, play a game, and so forth; in her day schedule, she has no time left. A befriended resident joined her in most of these activities.

Caregivers, more than the residents, emphasized the increased freedom of action and choice for residents and themselves compared to other care facilities. According to caregivers, residents had multiple options for spending their time and could choose whether or not they joined activities. Residents also had different common areas available, including outdoor places, and could choose to retreat in their private rooms.

Caregivers experienced more flexibility and control over how and when to complete tasks. They explained that, in this care organization, they had less rules to follow, did not always have to ask their directors permission to organize activities with residents, but could take more initiatives themselves. Caregivers considered this an opportunity to get to know residents well, to better attune to residents' capacities and preferences, and stimulate independence and counter boredom in them. Three caregivers contrasted this flexibility, control and increased personal contact with the less satisfactory "assembly line work" they had experienced in other facilities. For example:

There [i.e., in another facility] you continually had to wash [residents], [give them] medication, put [them] on the toilet

Until your shift was done

And here, you can have a nice chat in their room

Just do pleasant things at ease

Like you would do at home

And not so hasty

And not almost like assembly line work

You don't have that here

In summary, residents and caregivers experienced being less bound by time schedules and regulations, being more able to attune to personal capacities and preferences, and having more possibilities. In caregivers' accounts, this freedom was linked with an atmosphere they characterized as less stressful and hasty, more relaxed, pleasant, peaceful, and at ease.

\section{Living together}

Residents' freedom in Heather House allowed them to seek out some people, avoid others, or withdraw in a more private place. The researcher witnessed several sociable events, e.g., residents inviting each other around the table to chat, play games, or have coffee. Yet, residents also often withdrew in their private room - "a little house for your own", as one resident said -, a possibility valued by residents and caregivers.

Concerning the social aspect of living together, residents and caregivers also appreciated the limited number of residents per dwelling unit. In Heather House, residents "do not sit very close to each other", as one caregiver explained. Living together with eight people, rather than in a larger group, made social contact easier amongst residents, and between residents and caregivers. Interviews with residents and caregivers reflected understanding and acceptance amongst them, and indicated 
that caregivers could fulfill their role as residents' contact persons. Overall, they experienced more pleasant social dynamics in Heather House than in other facilities they knew.

Although residents liked to live within a little group, the interviews with them also revealed difficulties and discontentment on a social level. Moreover, most of them hardly showed a sense of belonging to the group of people in their dwelling unit. Two residents even dissociated themselves from co-residents. Living together with people who differ in terms of physical and cognitive capacities and mother tongue was not always easy, and for some residents very undesirable. Especially for those residents who were physically and cognitively rather strong, this seemed to play an important role in being dissatisfied with their stay in Heather House, as one women expressed:

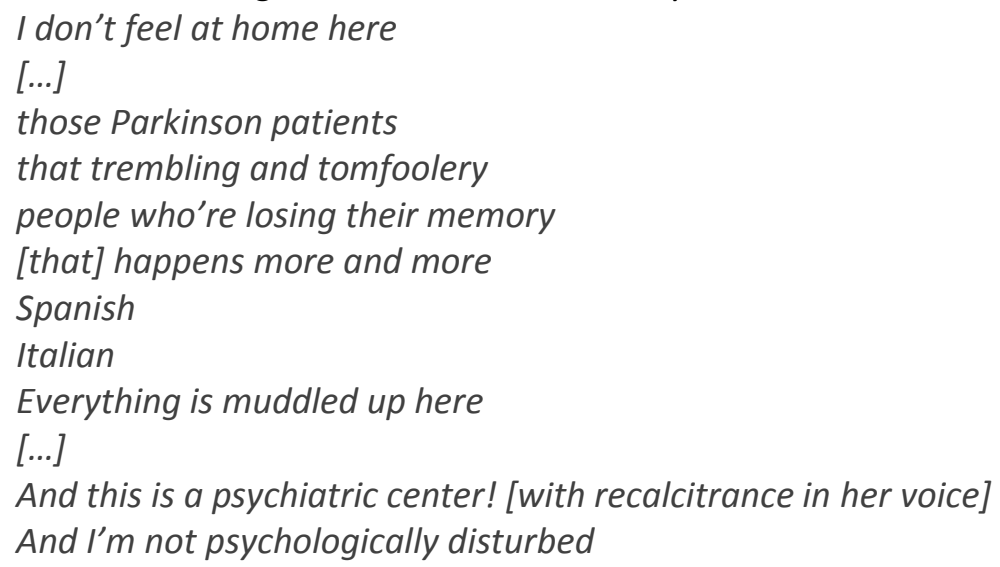

Interviews with caregivers indicated awareness and understanding of the fact that residents often retreated in their private rooms, and that living together was not always easy. Yet, they also emphasized the sociability in Heather House. They observed amongst residents sociable events that they rarely or not had found in more traditional, large-scale residential care facilities, e.g., going outside together to enjoy nice weather, and pleasant contacts between people from different dwelling units. Also the common activity of having coffee together was considered more enjoyable in Heather House due to the limited number of people, as explained above. Caregivers observed reduced tensions and less conflicts amongst residents.

\section{Hominess}

'Hominess', as used by caregivers, referred to an atmosphere they characterized as relaxed, pleasant, peaceful, or at ease. This atmosphere related to their experiences of freedom, living together, or the facility's residential character. The idea of hominess seemed to underlie their descriptions of their tasks as caregivers (including being a companion and contact person), their personal relation with residents, the places and activities available to residents, the facility's integration in a residential area, ..., and their overall image of Heather House as a place not only for care, but also for dwelling. Thus, 'hominess' was used as a catch-all term. The hominess at Heather House was often contrasted with more traditional, hospital-like, residential care buildings. This strong contrast, and given that hominess is an essential theme in their care vision, could explain why the caregivers were very positive about Heather House.

\section{The role of architectural features}

In our study, experiences of freedom, favorable social dynamics and hominess seem to relate to the architectural features of small-scaleness, spatial generosity and accessibility. Residents and caregivers experienced Heather House as being small-scale, in terms of number of people per dwelling unit, size (i.e., spatial articulation) and compactness. Yet, it was only in combination with a spatial generosity in terms of surface area, room to maneuver and variety of places that the building 
afforded experiences of freedom, favorable social contacts, and - for caregivers - hominess. In addition, they experienced significantly increased physical accessibility compared to other residential care facilities, although they still encountered some obstructions. Accessibility was considered important, down to the smallest construction detail, especially for less mobile persons.

\section{Small-scale, generous space}

Interviews with residents and caregivers indicated that the spatially compact setting was more easily negotiated and accessed by residents. Residents were involved in the whole dwelling unit, instead of just part of a larger ward, as one caregiver noted. At the same time, each dwelling unit provided enough room to maneuver (also with a wheelchair, wheeled walker or hoist), and safe and accessible outdoor places were available to residents. As such, small-scaleness and spatial generosity with respect to freedom of movement related to accessibility, which is further described below. Each dwelling unit included smaller, but multiple common rooms, each with specific equipment and furniture, which made them suitable for different activities. Residents and caregivers indicated that this made it possible and easy to organize, join, and choose between different activities, thus increasing their freedom of activity and choice.

Care givers considered the limited number of residents and compactness easier for them to manage. Combined with the spatial generosity, it enhanced flexibility and control; no strict rules and time schedules were needed.

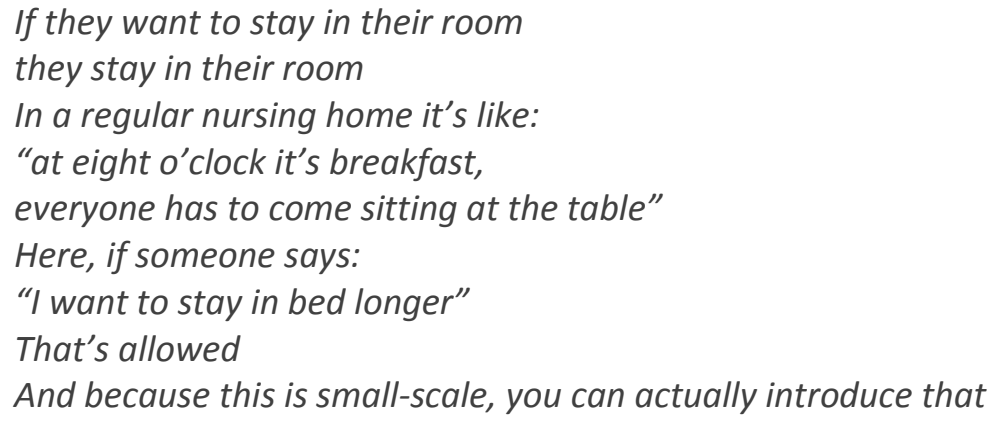

As mentioned, the limited number of residents per dwelling unit seemed to enhance favorable social contacts. At the same time, residents and caregivers noted, because of the available space residents did not sit very close to each other, figuratively and literally, for example, around the dining table. According to caregivers, less collisions between people and less intrusions in each other's personal space occurred, reducing conflicts and enhancing sociability, compared to traditional nursing homes they knew. Also the variety of places played a role on a social level. It allowed residents to seek out some people, avoiding others, or withdrawing in a more private place, and allowed caregivers to better attune to residents' capacities and preferences.

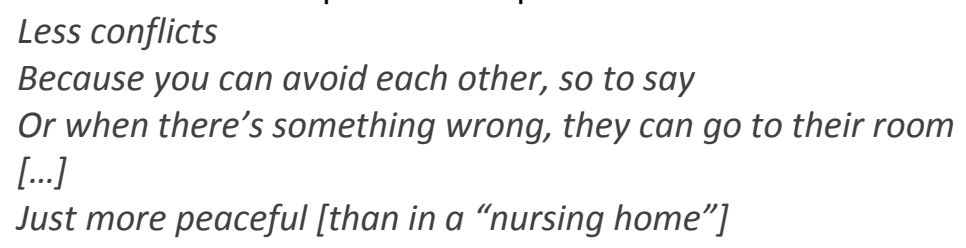

Additionally, caregivers mentioned that they could fulfill their role as contact persons for residents at any time. Indeed, the caregivers' desk was not assigned a separate room, but integrated in either the hobby room or the living room.

Besides more favorable social contacts in common rooms, the spatial generosity of residents' rooms offered them a high-quality private place, not "a small isolating cell", as one caregiver formulated it. Residents and caregivers spontaneously mentioned these rooms. They were considered large and well-arranged, and thus allowed residents to personalize it, move rather easily (also with a wheelchair), and do their own thing. 
Caregivers related the homey character to the availability of multiple common rooms (as opposed to just one large dining area), and their compact clustering in an open plan (Figure 1, c). One caregiver noted:

\section{If there were doors everywhere}

Then the homey character would be gone, I think

The multiple common rooms allowed caregivers to conduct "homey" activities (e.g., to make pancakes, which is difficult in large-scale nursing home with only a centralized kitchen).

From the outside, the building's small-scale and integration in the neighborhood made a residential, and homey impression on the caregivers. They compared it with apartments, houses, or villas. They appreciated that it did not look like a typical "old-people's-home." However, there was an ambiguity: it does not consist of ordinary houses, yet it is not a (common) care facility either. Despite this ambiguity, the image created by the architecture matched their care vision of small-scale, normalized living.

\section{Accessibility}

Accessibility enhanced freedom of movement, action and choice, and, consequently, also affected experiences of living together. It was of direct importance to residents, especially less mobile ones. But it also played a role for caregivers, since it supported a positive atmosphere by reducing obstructions and collisions. Accessibility concerned the building's spatial organization (including visual access), access to outdoors and to the neighborhood, and construction details.

Concerning spatial organization, the open plan, visual access, and number of floors stood out in the interviews. Openness fostered ease of access and experienced freedom. The open plan arrangement of each dwelling unit's common areas was positively appreciated by residents and caregivers. Doors would form obstructions, for residents (in wheelchairs), but also for caregivers, e.g., when distributing medicine.

The open plan and glazed patio enhanced visual access within the dwelling unit. According to two caregivers this helped residents to stay in contact with different places, (and see, e.g., when visitors entered,) and enhanced the dwelling unit's legibility. Visual access also helped caregivers to keep an eye on residents when needed. The many windows provided residents views on green and people passing by. Two residents highly appreciated the possibility to see and feel nature and to have contact with the neighborhood. One of them contrasted this quality with her stay on the fourth floor of another residential care facility:

because [in the other facility] you couldn't see anything from the fourth floor when we stayed up there, we didn't see anything, you know

in your room you were really shut in and here you're more free

The dwelling units at Heather House are located on only two floors. According to residents and caregivers this enhanced the access to outdoor places. Evidently, the ground floor offers the easiest access. On the first floor, one needs to pass a code-locked, little gate or door to reach respectively the staircase or elevator.

Access to the neighborhood was linked with experiences of freedom and social contacts. Residents appreciated the facility's integration in a regular residential street, yet they would have wanted better accessible public facilities, like a chapel, store, or café, to have available additional activities and social contexts.

Heather House is enclosed by a hedge and two code-locked, little garden gates, offering residents much appreciated, safe outdoor places. However, the enclosure reminded some of them of their limited freedom or that of co-residents, who did not know the codes. One interviewed resident - the most free of them all, because he could leave the facility independently - said that the site's 
enclosure gave him a feeling of being locked up. Besides, the steep pathways towards the garden gates are difficult for wheelchair users and their helpers, especially combined with the pushbutton to open the gate.

Accessibility concerning construction details included, e.g., level differences between inside and outside. Residents in wheelchairs experienced difficulties in entering the dwelling unit due to a one centimeter high doorstep. Even level differences of only a few millimeters between two floor materials had caused residents, who shuffled their feet, stumbling. Additionally, caregivers mentioned that color differences in floor materials had caused some residents with dementia hesitating to cross the different colored floor parts, as if there were a level difference.

\section{Discussion}

In societies with aging populations, the growing need for (re)new(ed) residential care facilities makes the study of how people experience them timely. Our case study of the role of architectural features in how resident and caregiver experience a newly built residential care facility contributes to a growing body of research that is relevant to social sciences and architectural design. The themes we derived stay close to the data. Situating them within a socio-historical context and linking them with available theoretical concepts yields broader insights and points of discussion.

Socio-historically, the emphasis on freedom exemplifies older and frail people's process of emancipation visible in societal discourses on dwelling and care (see introduction). Our results present the experiences of people compelled to move to a care facility due to health problems. They balance being free with being bound to a social and physical framework. This framework can either support or hinder freedom. Theoretically, this can also be understood in terms of the dialectic of autonomy and security (as defined by Parmelee and Lawton (1990, pp. 465-466): residents balanced "freedom of choice, action, and self-regulation of one's life space" with being "limited by, and aided by dependable physical, social, and interpersonal resources". The importance of both autonomy and security may explain why residents highly valued their private room. Indeed, a private room affords both (Van Steenwinkel, Baumers, \& Heylighen, 2012, p. 202).

Freedom of movement was the most important theme in residents' experiences relating to architecture. To date, the interventions implemented to prevent residents from running away, getting lost or injured, and to prevent wandering have been characterized by a restrictive, "antinomadic" (Tirado, Callen, \& Cassian, 2009, p. 373) type of care inside the care facility. In this way, constant supervision is needed and, thus, regulating risk and freedom of movement is a challenge shared by caregivers and residents (Tirado et al., 2009, p. 373). Yet, our study suggests that increasing freedom of movement by creating a safe and accessible environment is more pleasant and easy for residents and caregivers. Yet, this regained freedom in Heather House was only partial, since diversity amongst residents entails that supervision and safety measures needed for some residents also limit the (experienced) freedom of movement for others. Freedom of movement remains the subject of tensions and constant negotiation (Gilmour, Gibson, \& Campbell, 2003).

Caregivers at Heather House aim to realize a contemporary vision on dwelling and care, i.e., 'smallscale normalized living', which holds in its definition a strong emphasis on family-like group living within a household (Coomans, De Smet, \& Heylighen, 2011, p. 332). Our study challenges this idea of residents forming a household in residential care facilities. Indeed, we found amongst residents a limited sense of group belonging, and, even more, clear instances of 'othering', i.e. practices of setting a group of people apart as different (Lepianka, 2015, pp. 1098-1099; Mountz, 2009). On top of a variety in physical and cognitive abilities, residents had very different sociocultural backgrounds, and did not know or chose each other before moving into Heather House. Thus, they experienced 
'social freedom of movement', yet only within the boundary of the collective living setting, which was too limiting for some of them.

A family-like collective living might be preferable for some. Yet, considering diverse preferences amongst current and future residents, an environment that holds an ambiguity between private and collective living may be more sustainable. Even more, because we think that one perfect or correct design does not exist, a variety of residential care facilities in terms of private and collective living would enhance people's freedom of choosing a facility.

The emphasis on home and hominess in contemporary care discourses is a reaction against care institutions where residents/patients are subjected to rigid day schemes and regulations, have little autonomy, and are patronized and separated from society (Declercq, 2000; Elf et al., 2015; Mens \& Wagenaar, 2009; van der Kooij, 1987). "While such institutions", Hockey (1999) notes, "share the title of 'home', they have few attributes, spatial and social ones, of what one could call as an ideal home". Although the interviewed residents did not or hardly talked about Heather House as their home, they did emphasize freedom and favorable social dynamics, two aspects caregivers related to hominess. Thus, Heather House - small-scale, and generous in terms of space- may be considered as an example of how to introduce socio-spatial features of home.

Hominess is an important aspect of Heather House's care vision. Since caregivers had been hired for realizing this vision, they likely had a colored view, and the generally positive tenor in their accounts might indicate a trained and collectively spread narrative. However, their positive appreciations were underpinned by concrete examples. Thus, in the case of Heather House "both the architecture and the way the work environment is shaped by rules and expectations of conduct contribute to the narratives evoked by buildings" (Kearns, 2007, p. 127).

For caregivers Heather House had an ambiguous character of being a place for both dwelling and care. Our study showed that, despite some limitations, the architecture matched caregivers' vision on dwelling and care, and, thus, helped them realizing this vision. This tallies with the idea that a place can be defined as "a milieu comprising a physical setting within which activities occur [...] and having inherent yet largely implicit socially shared understandings that enable effective coaction" (Diaz Moore, 2004, p. 298).

Our case study provides insight into how architectural features may play a role in residents' and caregivers' experiences. Small-scaleness, spatial generosity and accessibility were the themes we used to capture multiple architectural features that appeared to have such role: spatial articulation, compactness, available room to maneuver, variety of places (indoor and outdoor), number of floors, open plan, etc. These features cannot be linked one-to-one with people's experiences. They need to be considered holistically (Calkins, 2001). Heather House is an example of how a residential care facility can be designed to foster freedom of movement, action, choice, social movement, as well as - at least for caregivers - a sense of hominess. In short it consists of a compact cluster of private rooms and multiple common rooms around a patio in an open plan; dwelling units are grouped in building blocks of two floors high, plus basement; it has articulated façades; and it is spatially integrated in the neighborhood (Figure 1). This case study contributes to an accumulative knowledge base of thoroughly studied architectural design strategies for residential care facilities. Such a knowledge base is expected to arm architects and professional caregivers involved with design for older people with a range of design strategies for thinking about new and improved designs.

Although residents and caregivers often contrasted Heather House with other facilities they knew, an in-depth comparative study has not been conducted. However, they specifically indicated Heather House's improvements compared to more "traditional" facilities, and its weaknesses that should be eliminated in future designs. Our study included a rather small and diverse sample of interviewees. Their diverse experiences might inspire further research on how residents' health 
condition or sociodemographic characteristics, and caregivers' education level affect their architectural preferences.

\section{Conclusion}

We aimed to gain insight into residents' and caregivers' experiences living and working in a residential care facility and the role of architectural features therein. Our analysis foregrounds an urge for emancipation, reflected in experiences of freedom of movement, action and choice, and social freedom of movement; values of high importance to residents and caregivers. However, for most residents, these forms of freedom were only available within the boundaries of the facility - a collective housing setting - to which they had been assigned. Our study shows how freedom can be enhanced by architectural features like small-scaleness, generosity and accessibility, while continuously balancing freedom, on the one hand, and safety and support on the other. Our study challenges the idea of family-like group living. Since we found limited sense of group belonging amongst residents, our findings suggest to rethink residential care facilities in terms of private or collective living in order to address residents' social freedom of movement.

'Hominess' in caregivers' accounts referred to freedom of movement, action and choice, to favorable social dynamics and the building's residential character. Being homey to caregivers, Heather House's architectural design matched their vision on dwelling and care and, thus, helped them realizing this vision.

\section{Acknowledgements}

We thank Heather House's residents, caregivers, directors and architects for their invaluable contributions to the study. We also like to thank Jos Benders, Koen Coomans, Rudiger De Belie and Lander Vermeerbergen for participating in peer debriefing.

This work was financially supported by Research Fund KU Leuven (OT/12/051 and PDM/16/091) and the architecture firm that designed Heather House.

\section{References}

Calkins, M. P. (2001). The physical and social environment of the person with Alzheimer's disease. Aging \& Mental Health, 5(sup001), 74-78.

Coomans, K., De Smet, H., \& Heylighen, A. (2011). In Search of a Future for Large-Scale Care Homes in Flanders. Journal of Housing For the Elderly, 25(4), 329-351. https://doi.org/10.1080/02763893.2011.621858

Crotty, M. (1998). The foundations of social research: meaning and perspective in the research process. London ; Thousand Oaks, Calif: Sage Publications.

Declercq, A. (2000). De complexe zoektocht tussen orde en chaos. Een sociologische studie naar de differentiatie in de institutionele zorgregimes voor dementerende ouderen.

Diaz Moore, K. (2004). Interpreting the "hidden program" of a place: An example from dementia day care. Journal of Aging Studies, 18(3), 297-320.

Diaz Moore, K., \& Geboy, L. (2010). The Question of Evidence: Current Worldviews in Environmental Design Research and Practice. Arq: Architectural Research Quarterly, 14(02), 105-114.

Dierckx de Casterlé, B., Gastmans, C., Bryon, E., \& Denier, Y. (2012). QUAGOL: A guide for qualitative data analysis. International Journal of Nursing Studies, 49(3), 360-371. https://doi.org/10.1016/j.ijnurstu.2011.09.012

Elf, M., Fröst, P., Lindahl, G., \& Wijk, H. (2015). Shared decision making in designing new healthcare environments-time to begin improving quality. BMC Health Services Research, 15(1). https://doi.org/10.1186/s12913-015-0782-7 
Flyvbjerg, B. (2011). Case Study. In D. Norman K. \& L. Yvonna S. (Eds.), The Sage Handbook of Qualitative Research (4th ed., pp. 301-316). Thousand Oaks, CA: Sage.

Geertz, C. (1993). Thick Description: Toward an Interpretive Theory of Culture. In The interpretation of cultures (reprint, revised, pp. 3-30). London: Fontana Press.

Gilmour, H., Gibson, F., \& Campbell, J. (2003). Living Alone with Dementia A Case Study Approach to Understanding Risk. Dementia, 2(3), 403-420. https://doi.org/10.1177/14713012030023008

Gubrium, J. (1978). Notes on the social organization of senility. Urban Life, 7(1), 23-44.

Hockey, J. (1999). The ideal of home: domesticating the institutional space of old age and death. In T. Chapman \& J. L. Hockey (Eds.), Ideal Homes?: Social Change and Domestic Life. London: Routledge.

Kearns, R. A. (2007). Creating a place for population health: Interpreting the spaces of a new School in Auckland, New Zealand. Social Science \& Medicine, 65(1), 125-137. https://doi.org/10.1016/j.socscimed.2007.02.051

Lawton, M. P., \& Nahemow, L. (1973). Ecology and the aging process. In C. Eisdorfer \& M. P. Lawton (Eds.), The psychology of adult development and aging. 619-674: American Psychiatric Association.

Lepianka, D. (2015). How similar, how different? On Dutch media depictions of older and younger people. Ageing and Society, 35(5), 1095-1113. https://doi.org/http://dx.doi.org.kuleuven.ezproxy.kuleuven.be/10.1017/S0144686X140001 42

Martin, D., Nettleton, S., Buse, C., Prior, L., \& Twigg, J. (2015). Architecture and health care: a place for sociology. Sociology of Health \& IIIness, 37(7), 1007-1022. https://doi.org/10.1111/14679566.12284

Mens, N., \& Wagenaar, C. (2009). De architectuur van de ouderenhuisvesting: bouwen voor wonen en zorg. Rotterdam: NAi Uitgevers.

Mountz, A. (2009). The other. In Key Concepts in Political Geography (Vol. Chapter 28). London: SAGE Publications Ltd. Retrieved from http://knowledge.sagepub.com/view/key-concepts-inpolitical-geography/SAGE.xml

Parmelee, P. A., \& Lawton, M. P. (1990). The design of special environments for the aged. In J. E. Birren \& K. W. Schaie (Eds.), Handbook of the psychology of aging (3th ed., pp. 464-488). London: Academic Press.

QSR International. (2015). NVivo (Version 11). QSR International. Retrieved from www.qsrinternation.com

Rowles, G. D., \& Chaudhury, H. (Eds.). (2005). Home and Identity in Late Life: International Perspectives. New York: Springer Publishing Company.

Schwarz, B. (2012). Environmental Gerontology: What Now? Journal of Housing For the Elderly, 26(1-3), 4-19. https://doi.org/10.1080/02763893.2012.673374

Tirado, F., Callen, B., \& Cassian, N. (2009). The Question of Movement in Dwelling: Three Displacements in the Care of Dementia. Space and Culture, 12(3), 371-382.

United Nations, Department of Economic and Social Affairs. (2015). World Population Ageing 2015 Highlights. Retrieved from http://www.un.org/en/development/desa/population/publications/pdf/ageing/WorldPopul ationAgeing2015_InfoChart.pdf

Van Audenhove, C., Declercq, A., De Coster, I., Spruytte, N., Molenberghs, C., \& Van den Heuvel, B. (2003). Kleinschalig genormaliseerd wonen voor personen met dementie. Antwerpen, Belgium: Garant.

Van den Bosch, K., Willemé, P., Geerts, J., Breda, J., Peeters, S., Van De Sande, S., ... Stordeur, S. (2011). Toekomstige behoefte aan residentiële ouderenzorg in België: Projecties 2011-2025. KCE Belgium Health Care Knowledge Center. Retrieved from https://kce.fgov.be/sites/default/files/page_documents/KCE_167A_residentiele_zorg_in_Be Igie.pdf 
van der Kooij, C. (1987). Van oude mensen vroeger en nu: over de geschiedenis van de ouderdom en de zorg voor oude mensen. Deventer: Van Loghum Slaterus.

Van Steenwinkel, I., Baumers, S., \& Heylighen, A. (2012). Home in Later Life: A Framework for the Architecture of Home Environments. Home Cultures, 9(2), 195-217.

Van Steenwinkel, I., Verstraeten, E., \& Heylighen, A. (2016). Adjusting an older residential care facility to contemporary dementia care visions. In P. Langdon, P. Robinson, J. Lazar, \& A. Heylighen (Eds.), Designing around people. London: Springer-Verlag.

Wahl, H.-W., \& Weisman, G. D. (2003). Environmental Gerontology at the Beginning of the New Millennium: Reflections on Its Historical, Empirical, and Theoretical Development. The Gerontologist, 43(5), 616-627. https://doi.org/10.1093/geront/43.5.616

Weisman, G. D. (1997). Environments for Older Persons with Cognitive Impairments. In G. T. Moore \& R. W. Marans (Eds.), Toward the Integration of Theory, Methods, Research, and Utilization (pp. 315-346). Springer US. https://doi.org/10.1007/978-1-4757-4425-5_10

Weisman, G. D., Calkins, M., \& Sloane, P. (1994). The environmental context of special care. Alzheimer Disease and Associated Disorders, 8 Suppl 1, S308-320.

Weisman, G. D., Chaudhury, H., \& Diaz Moore, K. (2000). Theory and practice of place: toward an integrative model. In The many dimensions of aging: Essays in honor of M. Powell Lawton (pp. 3-21). New York: Springer. 